\title{
Experimental analysis of a bubbling fluidized bed gasification plant fed by biomass: Design, implementation and validation of the control system
}

\author{
Carlos Vargas-Salgado ${ }^{1, *}$, Lina Montuori $^{1}$, and Manuel Alcázar-Ortega ${ }^{1}$ \\ ${ }^{1}$ Institute for Energy Engineering, Universitat Politécnica de València, Camino de Vera, s/n, 8E-F-5, \\ 46022 Valencia (Spain)
}

\begin{abstract}
Despite being a renewable source, biomass as fuel for power generation is still not completely exploited. In biomass gasification plants, control operations are crucial for the proper management of the plant. This paper describes the results of a regulation control applied to an experimental biomass bubbling fluidized bed (BFB) gasification plant. The aim of implementing the system is to improve the biomass gasification process, increasing the efficiency and ensuring the safety in the plant operation. The equivalence ratio (ER) is one of the main parameters in a gasification process. To improve the ER, the airflow input is controlled, measuring the air velocity through an anemometer. On the other hand, the biomass flow is controlled modifying the speed of the screw conveyor using an inverter for regulating the frequency of its electric motor. A PLC is used for programming the instructions to implement control functions and to store the data given by the measurement devices. Once implemented the control system, the biomass gasification plant could work either; manually o automatically, allowing to adjust ER, increasing efficiency of the process. Finally, some tests are done to validate the control system, using the acquired data to improve the process.
\end{abstract}

\section{Introduction}

The use of renewable energy sources allows fossil fuels to be drastically reduced, thus cutting the emission of greenhouse gases in the atmosphere. Every MWh produced from renewable sources prevents up to $106 \mathrm{~kg}$ of $\mathrm{CO}_{2}$ emissions [1]. In this way, biomass gasification for energy production could be a promising renewable source. Despite this, biomass gasification is not a widely used process for power generation. Improving the control system of biomass bubbling fluidized bed gasifiers (BFB) would partially help to increase the viability of this kind of plants and hence its use.

Several previous works show simulations and experimental results about the control of other similar processes such as combustion [2] [3] [4] [5]. On the other hand, some publications show the results based on simulation about the control of the biomass gasification process, mainly applied to a downdraft gasifier [6] [7] [8] [9] [10]. The novelty of this paper resides on the design of a control system for a BFB gasification plant to improve the gasification process, which has been validated in field tests that have demonstrated an increment in efficiency and safety.

\footnotetext{
* Corresponding author: carvarsa@ upvnet.upv.es
} 
To analyse the gasification process, data processing is required. The core of the automation system is a Programmable Logic Controller (PLC). The modular design of this PLC enables the extension with a wide range of digital and analogue I/O modules [11] [12].

On the other hand, the equivalence ratio (ER) is the relation between the oxygen content in the oxidant supply and that required for the complete stoichiometric combustion. This is likely the most important operating parameter for all thermal processes since it strongly affects the gas composition (including tar content) and its heating value [13] [14] [15]. In the tests carried out the ER was controlled by a PLC, using the Modbus protocol to communicate different devices of the plant for obtaining data and supervising the process.

Regarding the structure of the document, the second point explains the biomass gasification plant tested and the biomass used. The third and fourth points give information on the measuring devices and the automation control system used. The fifth point explains the methodology and finally the point sixth and seventh show the results and conclusions.

\section{Experimental plant and testing set up}

\subsection{BFB gasification plant and biomass tested}

The test has been carried employing an experimental $10 \mathrm{kWe}$ BFB gasification plant. The fuel produced is used to power generation through a Genset, which was adapted for running using syngas as a fuel. Table 1 shows the main parameters of the gasification plant under study, and Table 2 shows the characteristics of the Genset.

Table 1. BFB Biomass gasification plant characteristics

\begin{tabular}{|c|c|}
\hline Rated electrical power & $10 \mathrm{~kW}$ \\
\hline Syngas production* & $27-33 \mathrm{~m} 3 / \mathrm{h}$ \\
\hline Syngas LHV & $4,000-6,000 \mathrm{~kJ} / \mathrm{m} 3$ \\
\hline Biomass consumption** & $13 \mathrm{~kg} / \mathrm{h}$ \\
\hline Equivalence Ratio (ER) & $0.25-0.35$ \\
\hline Efficiency* & $70 \%$ \\
\hline
\end{tabular}

\footnotetext{
*at maximum load.

$* *$ at maximum load (Moisture $=7 \%$ ).

$* * *$ at maximum load (Biomass to syngas conversion).
}

Table 2. Genset characteristics

\begin{tabular}{|c|c|}
\hline Engine type & $\begin{array}{c}\text { Four-stroke } \\
\text { engine }\end{array}$ \\
\hline Number of cylinders & 4 \\
\hline $\begin{array}{c}\text { Rated power (natural } \\
\text { gas) }\end{array}$ & $14 \mathrm{~kW}$ \\
\hline Rated Power (Syngas) & $10 \mathrm{~kW}$ \\
\hline RPM & 1,500 \\
\hline Compression Ratio & $8.5: 1$ \\
\hline $\begin{array}{c}\text { Efficiency at maximum } \\
\text { load }\end{array}$ & $17 \%$ \\
\hline
\end{tabular}


The biomass tested is pellets; the characteristics of the pellets used as a primary fuel are shown in Table 3.

Table 3. Characterisation of the tested biomass

\begin{tabular}{|c|c|}
\hline Kind of Biomass & Pellets \\
\hline Moisture (\%wt) & 7 \\
\hline $\begin{array}{c}\text { Bulk Density } \\
\text { (kg/m3) }\end{array}$ & 690 \\
\hline Ash (\%wt) & 2 \\
\hline VM (\%wt) & 76 \\
\hline FX (\%wt) & 15 \\
\hline C (\%) & 47 \\
\hline H (\%) & 6.3 \\
\hline N (\%) & $0.01-0.08$ \\
\hline O (\%) & 45 \\
\hline LHV (MJ/kg dry) & 16 \\
\hline
\end{tabular}

\subsection{Measuring devices}

The control system manages the processes according to the received inputs, in a feedback system where the collected information is managed. The air velocity is measured utilizing an anemometer that sends a 4-20mA signal to the CJ1W -MAD42 module integrated into the PLC OMRON CJ2M (Figure 1). Then the current signal is scaled to obtain the value of the air velocity. By means of this data, it is possible to calculate: the airflow, the fluidization velocity, the required biomass flow and to set the RPM of the electric motor. The gas composition and the LHV was determined by the portable infrared gas analyzer model Gasboard-3100p.

The electrical parameters were acquired employing 2 power meters (Siemens SENTRON PAC 3200). The Power meters send data to the PLC through the MODBUS TCP/IP protocol through the OMRON CJ1W-ETN21 Ethernet module.

Other measuring devices are thermocouples (to measure the temperatures into the reactor and heat exchanger) and pressure transductors (to measure the pressure drop into the reactor, heat exchanger and filters).

\subsection{Automation, control, and acquisition system}

To improve the gasification process, an automation, control, and data acquisition system was implemented. In this manner, it was possible to analyze the data to set the parameter for proper operation of the plant. The PLC used is a CJ2M OMRON. An HMI touchscreen (OMRON NS series) was used to visualize information from the process and to control manually the process. The architecture of the system is shown in figure 1. The PLC was programmed to implement control functions, such as logic, sequencing, timing, counting, arithmetic, etc. It controls the process through digital and analogue input/output and communications protocols. The central processing unit (CPU) interprets the input signals and carries out the control actions, according to the PLC programming, then it communicates the actions to the outputs [16]. 
Modbus RS485 protocol was used to control the vacuum pump and the screw conveyor through two inverters. Both are governed according to the PLC instructions, allowing to adjust ER. Figure 2 shows the reactor and location of the anemometer, vacuum pump and screw conveyor. ER is estimated knowing the elemental composition of the biomass according to equation 2 and controlling the airflow and the biomass flow as will be explained in the methodology).

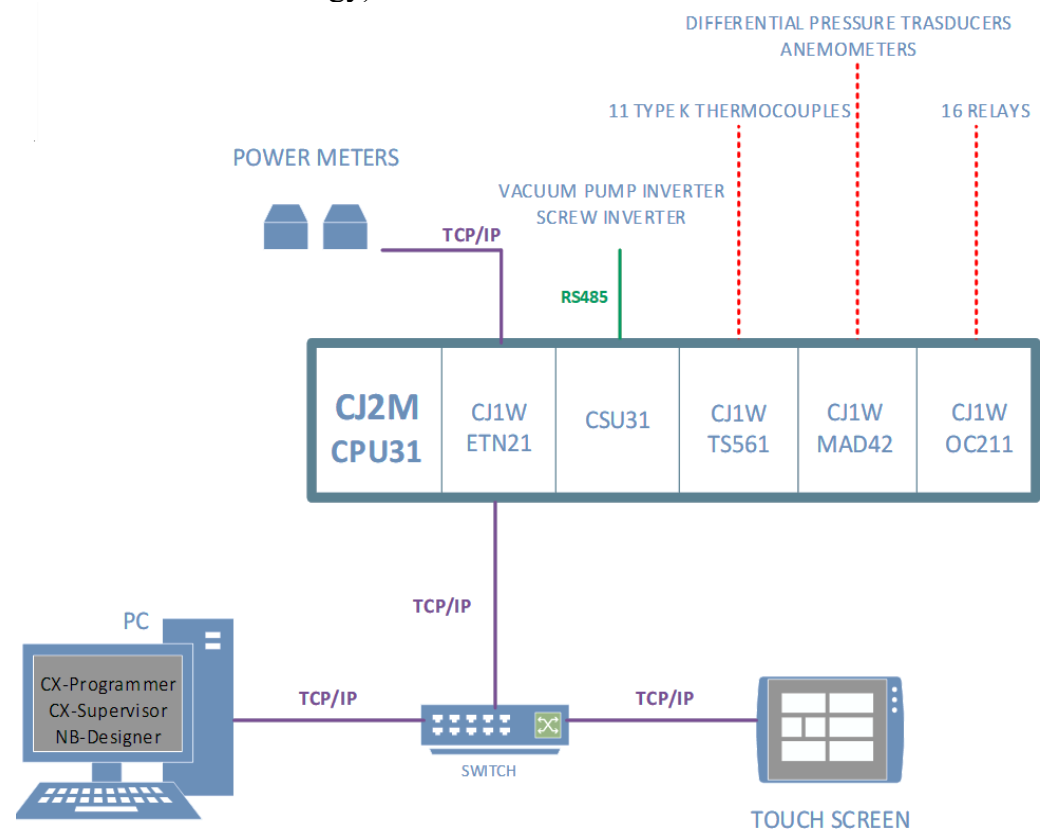

Fig. 1. The architecture of the automation, control and acquisition system.

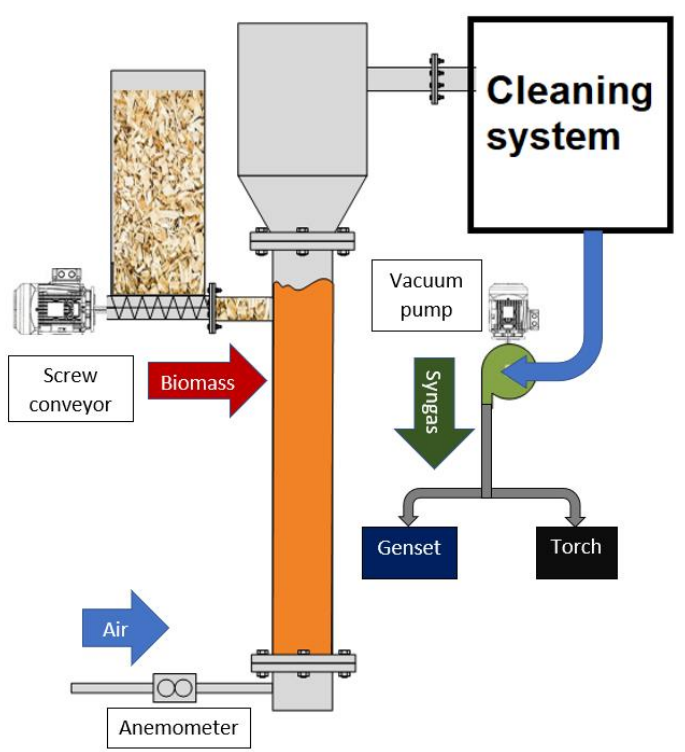

Fig. 2. Reactor and location of the anemometer, vacuum pump and screw conveyor. 


\section{Methodology}

In this section, the methodology to test de control system is explained. Two control modes were performed: manual and automatic. In both modes, biomass flow is a function of the screw conveyor motor frequency through a correlation that mainly depends on the biomass bulk density. Several tests were performed to obtain the biomass flow as a function of the screw conveyor motor frequency (Table 4 and Figure 2). Eq. (1), obtained from the test, shows the frequency required in the screw conveyor motor as a function of the dry biomass flow.

$$
f_{\text {screw }}=\frac{M_{\text {dry }}+0,2414}{0,228}(\mathrm{~Hz})
$$

Eq. (1) refers to dry biomass flow as only the heating value of dry biomass is considered. Dry biomass flow was calculated knowing the wet biomass flow and its moisture calculated through the proximate analysis test (see Table 3). The results are shown in Table 4 and in Fig.3. The electrical motor is coupled to a gearbox reducing in a 200:1 ratio the RMPs of the screw conveyor.

Table 4. Relationship between the rpm of screw conveyor and the biomass flow

\begin{tabular}{|c|c|c|c|c|}
\hline $\mathbf{f}(\mathbf{H z})$ & \multicolumn{2}{|c|}{ RPM } & \multicolumn{2}{c|}{ Biomass flow (kg/h) } \\
\hline Screw & Motor & Screw & Wet & Dry \\
\hline 25 & 675 & 3,38 & 5,9 & 5,5 \\
\hline 35 & 945 & 4,73 & 8,2 & 7,7 \\
\hline 40 & 1.080 & 5,40 & 9,5 & 8,7 \\
\hline 45 & 1.215 & 6,08 & 10,6 & 9,9 \\
\hline 50 & 1.350 & 6,75 & 12,1 & 11,3 \\
\hline 60 & 1.620 & 8,10 & 14,4 & 13,4 \\
\hline
\end{tabular}

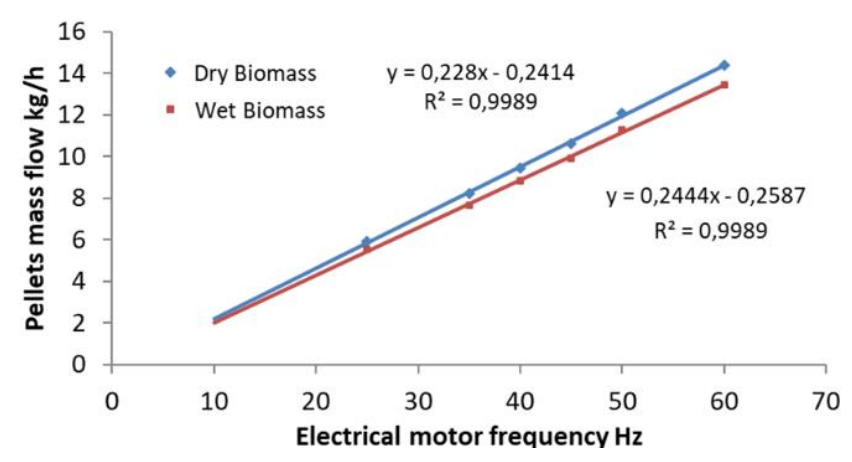

Fig. 3. Pellets mass flow vs frequency of the screw

\subsection{Manual operation}

Manual operation allows controlling the vacuum pump and the motor of the screw conveyor independently, letting to adjust the air/fuel ratio and the ER when new types of 
biomass are tested. To control de vacuum pump or the screw conveyor RPM, the frequency inverter is set through the HMI to respectively adjust the desired airflow and biomass flow.

\subsection{Automatic operation}

To find the proper ER, airflow must be calculated by measuring the air velocity through a hot wire anemometer located in the air intake pipe (Figure 2). According to the airflow, the PLC estimates (for the optimum ER) the set of the biomass flow. Then, the PLC set the frequency of the screw conveyor motor. In automatic operation, it is possible to burn the syngas in the torch (mainly to carry out the test in the plant) or to run the Genset for power generation.

\subsubsection{Automatic operation burning the syngas in the torch}

When the gasification plant operates in automatic mode burning the syngas in the torch, the PLC read the air velocity from the anemometer and estimates the proper set of velocity. Then, it writes the estimated frequency value on the holding register of the vacuum pump inverter VF1 (OMRON V1000 model), increasing or decreasing the velocity of the vacuum pump motor to maintain the desired biomass flow. The PLC controls the air/biomass ratio using the PID function, which controls the vacuum pump. The scheme of the automatic operation when the syngas is burnt in the torch is shown in figure 4. The inputs are ER, biomass moisture (w) and dry biomass flow (Mdry). The output is the frequency of the vacuum pump required to keep the ER desired.

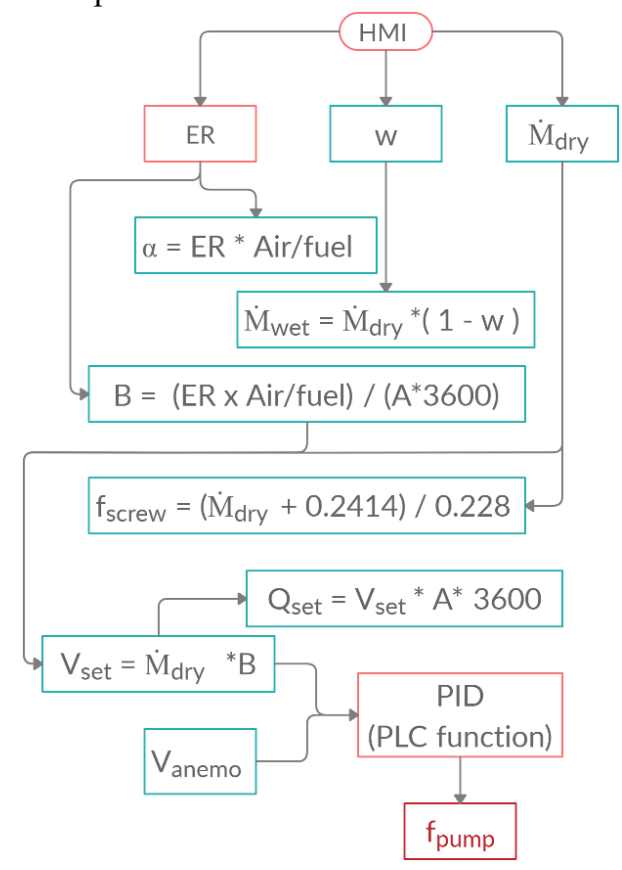

Fig. 4. Automatic operation when the syngas is burnt in the torch. 
An application example according to figure 4 is shown below:

- Employing the HMI touchscreen, Mdry is set to $8 \mathrm{~kg} / \mathrm{h}$, w to $7 \%$ (Table III) and ER to 0.27 . This value could be set manually or automatically.

- The Air/fuel ratio in $\mathrm{Nm} 3 / \mathrm{kg}$ is estimated for the gasification process through Equation 2 [17]. According to the elemental composition given in Table III and using the air density equal to $1,2 \mathrm{~kg} / \mathrm{Nm} 3$, the air/fuel ratio is equal to $4,66 \mathrm{Nm} 3 / \mathrm{kg}$.

$$
\begin{gathered}
T_{\mathrm{s}}(l, t)=T_{\mathrm{g}}(l, t) \\
\frac{\text { Air }}{\text { Fuel }}=\frac{137,3}{\rho}\left(\frac{[\mathrm{C}]}{12}+\frac{[\mathrm{H}]}{4}-\frac{[O]}{32}\right)
\end{gathered}
$$

- $\quad$ Through equation (1), electrical motor frequency of the screw conveyor is calculated.

- According to Mdry, $\alpha$ and A (in this case A=0.001941 m2), PLC calculates the set velocity (Vset $=1.4314 \mathrm{~m} / \mathrm{s}$ ), and the set of the airflow (Qset $=10 \mathrm{~m} 3 / \mathrm{h}$ ).

- Through PID function, by acting on vacuum pump motor frequency, real velocity is maintained close to the SET value, keeping the desired ER.

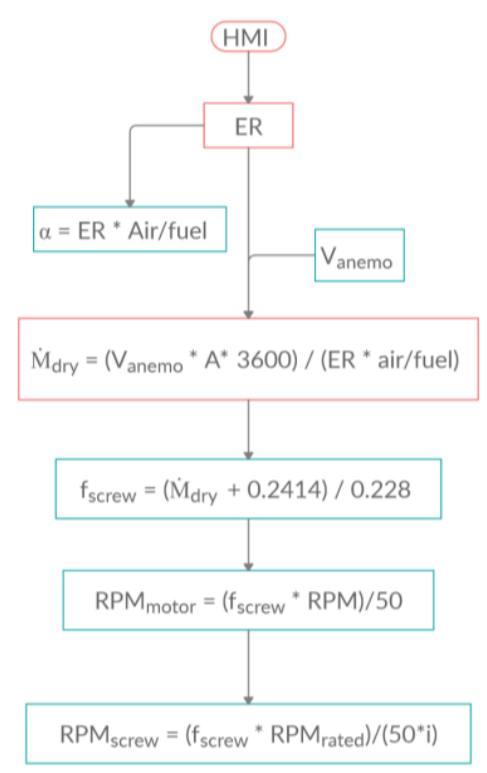

Fig.5. Automatic operation when the syngas runs the Genset.

\subsubsection{Automatic operation when the Genset is running on syngas for power generation}

On the other hand, when the internal combustion engine is running on syngas, the vacuum produced into the reactor is provoked by the engine suctions. The syngas sucked by the 
engine, and the air going into the reactor for the gasification process are linked as the Genset provoked vacuum into the reactor making air going into the plant (See Figure 2). When the electrical load increase, more gas is sucked by the engine and more air is introduced into the reactor. To keep the ER, the PLC modifies the set of biomass flow as a function of the airflow going into the reactor. The process is shown in figure 5 . The engine suction imposes the quantity of air going into the reactor (measured by the anemometer). The screw conveyor, through the inverter, sets the amount of biomass to go into the reactor to maintain the air-fuel ratio.

\section{Experimental Results}

After carrying out the tests, it was possible to automate properly the operation of the biomass gasification plant. Thanks to the system of acquisition and control, it was possible not only to adjust ER but also to keep it, improving the process, the safety and increasing the efficiency.

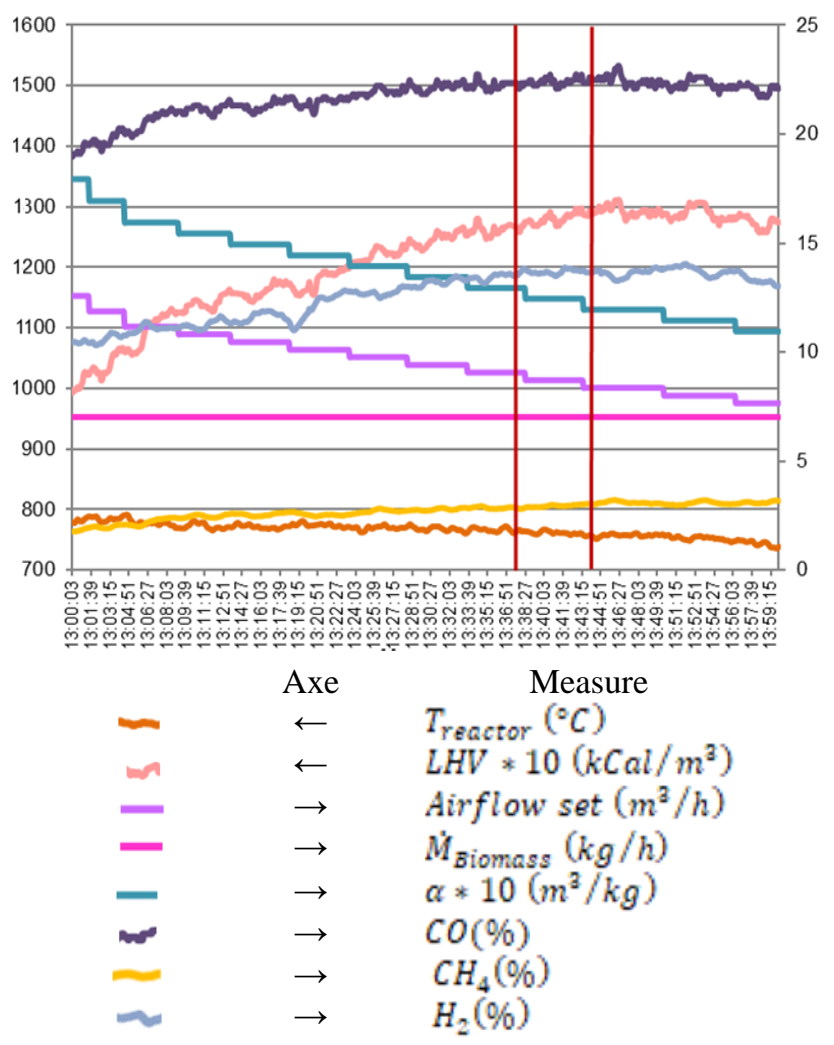

Fig.6. Operation of the gasification plant

Fig. 6 shows the results of the test in the automatic operation mode. The experiment consisted in to keep the biomass flow in a fixed value (in this case $7 \mathrm{~kg} / \mathrm{h}$ ), while the set of ER was decreased from 0.33 to 0.21 in steps of 0.01 . Then, it was possible to determine the ER and $\alpha$, that provides the higher LHV of the syngas produced (through the syngas composition obtained from the gas analyzer). To obtain a proper LHV, $1.20-1.30 \mathrm{~m}^{3}$ air 
$/ \mathrm{kg}$ biomass are required. Therefore, the ER must be ranged from 0.26 to 0.28 . The PCL scans the data all the time, and it acts to obtain such values according to Table 5.

Table 5. Air-Fuel ratio vs ER
\begin{tabular}{|c|c|}
\hline ER & $\begin{array}{c}\text { Air/fuel ratio } \\
(\boldsymbol{\alpha})\end{array}$ \\
\hline 0.33 & 1.55 \\
\hline 0.32 & 1.50 \\
\hline 0.31 & 1.45 \\
\hline 0.30 & 1.40 \\
\hline 0.29 & 1.35 \\
\hline 0.28 & 1.30 \\
\hline 0.27 & 1,25 \\
\hline 0.26 & 1.20 \\
\hline 0.25 & 1.15 \\
\hline 0.24 & 1.10 \\
\hline
\end{tabular}

\section{Conclusions}

To improve the gasification plant process and to ensure the safety in operation, an automation, control, and data acquisition system was designed, implemented, and tested. After carrying out the work, it can be concluded:

- The control system allowed controlling the process, mainly in two different kinds of services: manual and automatic.

- The manual operation allowed controlling the vacuum pump and the screw conveyor independently, to adjust the equivalence ratio when a new type of biomass need to be tested, or when other kinds of tests are required.

- Through the manual operation, it was possible to determine the correlation between the biomass flow and the screw motor frequency. It mainly depends on the biomass bulk density.

- Through tests in automatic operation, it was possible to determine the ER that provides the higher LHV value of the syngas produced (over $6,200 \mathrm{~kJ} / \mathrm{Nm}^{3}$ ). The tests determined that, to obtain the best LHV for the biomass tested, an air/fuel ratio range from 1.2 to $1.3 \mathrm{~m}^{3} / \mathrm{kg}$ is required. ER goes from 0.26 to 0.28 .

- In automatic operation burning the syngas, the PLC controls the air-fuel ratio using the PID function, which controls the vacuum pump motor to maintain the proper ER according to the biomass flow.

- In automatic operation running the Genset on syngas, the engine imposes, by the suction provoked into the gasification plant, the quantity of air to go into the reactor. Then, the PLC acts and the screw conveyor adjusts the amount of biomass to keep the ER in the desired value. 


\section{Acronyms and abbreviations}

\begin{tabular}{|c|c|c|}
\hline $\mathbf{A}$ & Area of the pipe where the anemometer is located. & $\mathrm{m} 2$ \\
\hline Air/fuel & Air-biomass ratio & $\mathrm{Nm} 3 / \mathrm{kg}$ \\
\hline BFB & Bubbling Fluidised Bed & \\
\hline ER & Equivalent Ratio & - \\
\hline fpump & Frequency of the vacuum pump motor & $\mathrm{Hz}$ \\
\hline fscrew & Frequency of the screw conveyor motor & $\mathrm{Hz}$ \\
\hline $\mathbf{F X}$ & Fixed Carbon & $\%$ \\
\hline HMI & Human Machine Interface & \\
\hline $\mathbf{i}$ & Gear ratio & \\
\hline $\mathbf{I} / \mathbf{O}$ & input/output & \\
\hline ICE & Internal Combustion Engine & \\
\hline LHV & Low Heating Value & $\mathrm{kJ} / \mathrm{kg}$ \\
\hline Mdry & Mass flow of dry biomass & $\mathrm{kg} / \mathrm{h}$ \\
\hline Mwet & Mass flow of wet biomass & $\mathrm{kg} / \mathrm{h}$ \\
\hline PLC & Programmable Logic Controller & \\
\hline PM & Power Meter & \\
\hline RPMrated & Rated RPM of screw motor & \\
\hline RPMscrew & RPM of the screw conveyor & \\
\hline RPM & Revolutions per minute & \\
\hline RTU & Remote Terminal Unit & \\
\hline SCADA & Supervisory Control and Data Acquisition & \\
\hline TCP/IP & Transmission Control /Internet Protocol & \\
\hline UTP & Unshielded Twisted Pair & \\
\hline Vanemo & Velocity given by the anemometer in real time & \\
\hline $\mathbf{V M}$ & Volatile Matter & \\
\hline$\rho$ & Air density & $\mathrm{Kg} / \mathrm{Nm}^{3}$ \\
\hline$\%$ wt & $\%$ in weight & \\
\hline
\end{tabular}

\section{References}

1. R. Bayindir and Y. Cetinceviz, A water pumping control system with a programmable logic controller (PLC) and industrial wireless modules for industrial plants--an experimental setup, 2011.

2. R. Suntivarakorn and W. Treedet, "Improvement of Boiler's Efficiency Using Heat Recovery and Automatic Combustion Control System," Energy Procedia, vol. 100, pp. 193-197, 2016.

3. L. Valente, L. Tarelho and V. Costa, "Emissions mitigation by control of biomass feeding in an industrial biomass boiler," Energy Reports, vol. 6, pp. 483-489, 2019. 
4. P. Sunil, K. Deal, B. Jayesh and P. Nataraj, "An experimental case study of robust cascade two-element control of boiler drum level," ISA Transactions, vol. 96, pp. 337$351,2020$.

5. L. Böhler, J. Krailb, G. Görtler and M. Kozek, "Fuzzy model predictive control for small-scale biomass combustion furnaces," Applied Energy, vol. 276, 2020.

6. L. Hui, "Improved fuzzy cascade control based on hybrid PSO algorithm for biomass gasifier," Chinese Journal of Scientific Instrument, 2011.

7. A. Sanjeevi Gandhi, T. Kannadasan and R. Suresh, "Biomass Downdraft Gasifier Controller Using Intelligent Techniques," in Gasification for Practical Applications, intechopen, 2012.

8. M. Costa, V. Rocco, C. Caputo, D. Cirillo, G. L. V. M. Di blasio, G. Martoriello and R. Tuccillo, "Model based optimization of the control strategy of a gasifier coupled with a spark ignition engine in a biomass powered cogeneration system," Applied Thermal Engineering, vol. 160, 2019.

9. F. Elmaz and Ö. Yücelb, "Data-driven identification and model predictive control of biomass gasification process for maximum energy production," Energy, vol. 195, 2020.

10. A. N. Kozlov, N. V. Tomin, D. N. Sidorov, E. E. S. Lora and V. G. Kurbatsky, "Optimal Operation Control of PV-Biomass Gasifier-Diesel-Hybrid Systems Using Reinforcement Learning Techniques," Energies, pp. 1-20, 2020.

11. A. Carullo and A. Vallan, Outdoor Experimental Laboratory for Long-Term Estimation of Photovoltaic Plant Perfomance, Milano, 2012.

12. K. M. Muttaqi, A. Esmaeel, J. Aghaei and V. Ganapathy, "Control issues of distribution system automation in smart grids," vol. 37, pp. 386-396, 2014.

13. N. Xue, Z. Wang, J. Wu, T. He, J. Zhang, J. Li and J. Wu, "Effect of equivalence ratio on the $\mathrm{CO}$ selectivity of Fe/Ca-based oxygen carriers in biomass char chemical looping gasification," Fuel, vol. 252, pp. 220-227, 2019.

14. J. Cespiva, M. Wnukowski, L. Niedzwiecki, J. Skřínský, J. Vereš, T. Ochodek, H. Pawlak-Kruczek and K. Borovec, "Characterization of tars from a novel, pilot scale, biomass gasifier working under low equivalence ratio regime," Renewable Energy, vol. 159, pp. 775-785, 2020.

15. G. Niv, Accurate modeling of Modbus/TCP for intrusion detection in SCADA systems, Tel Aviv, 1990.

16. A. Da'na, A. Sagahyroon, A. A.-A. Elrayes and R.Al-Aydi, Development of a monitoring and control platform for PLC-based applications, vol. 30, Computer Standard \& Interfaces, 2008.

17. C. Vargas-Salgado, "Estudio Comparativo de la Utilización de las Tecnologías DE Gasificación Downdraft y Lecho Fluido Burbujeante para la Generación DE Energía Eléctrica en Aplicaciones de Baja Potencia," p. 312, 2012. 